\title{
Chapter 1 \\ Introduction: Situating Children of Migrants Across Borders and Origins
}

\author{
Claudio Bolzman, Laura Bernardi, and Jean-Marie Le Goff
}

\subsection{Introduction}

Immigration is a substantive part of twentieth-century European history. Some countries, such as France and Switzerland, became popular destinations for immigrants at the beginning of the last century. Economically based migration of guest workers has become highly relevant in many other Western European countries (Great Britain, Germany, the Netherlands, Belgium, etc.) since the end of World War II (Piore 1979). The fall of the Berlin Wall, the extension of the European Community to Eastern European countries in the context of economic globalization on the one hand, and the conflicts in the former Yugoslavia and the Middle East on the other hand, accelerated both economic immigration and the arrivals of refugees at the beginning of the twenty-first century.

The sociologist Abdelmalek Sayad underlined the fact that even temporary migration necessarily becomes permanent migration: "There is no immigration, even supposedly for work and work alone (...) that does not transform into family migration (or) migration for settlement" (1991:19, our translation). Migrants' settlement comes along with marriages and children; these children may immigrate

\footnotetext{
C. Bolzman $(\bowtie)$

National Centre of Competence in Research LIVES - Overcoming Vulnerabilty: Life course perspectives (NCCR LIVES), University of Applied Sciences and Arts Western Switzerland, Genève, Switzerland

e-mail: claudio.bolzman@hesge.ch

L. Bernardi • J.-M. Le Goff

National Centre of Competence in Research LIVES - Overcoming Vulnerability: Life course perspectives (NCCR Lives), University of Lausanne, Lausanne, Switzerland

e-mail: laura.bernardi@unil.ch; jean-marie.legoff@unil.ch
} 
with their parents or be born in the host country, and they compose the second generation. Unlike their parents, the children of migrants are socialized in the host country and are exposed to its social institutions starting at early ages; as time goes by, they go to school, enter the labor market, get married, and become parents themselves. Although a growing number of studies have been devoted to the children of migrants, the methodological challenges related to research on these populations still remain implicit, as they are quite unexplored. Therefore, this volume on the children of migrants is intended to clarify the methodological issues that researchers face in producing and to analyzing relevant empirical data on the life courses and living situations of the children of migrants. Although the cases presented in these chapters are drawn mainly from European contexts, the insights gained are relevant in other areas of the world. The quality of scientific data is central for the elaboration of informed social and integration policies at the international, national, regional, and local levels.

Four major sections form the structure of the book. The first section explores comparison and comparability issues. The second section focuses on the life-course perspective and on the use of mixed methods in the study of children of immigrants. The third section is devoted to the use of qualitative methods to grasp the way in which the descendants of migrants navigate through various aspects of their identities (e.g., family relationships with the country of origin, socialization institutions in the host country, peer groups, and symbolic belonging) in the process of building their own identity or their own biography. The fourth and last section looks at the necessity of overcoming the dominant methodological nationalism and of developing transnational approaches in this area.

\subsection{Comparison as a Key Methodological Tool and a Challenging Perspective in the Study of the Children of Migrants}

Durkheim (1904), in his classical work on "the Rules of the Sociological Method," observed that comparison is a central methodological tool in the social sciences. His disciples, Fauconnet and Mauss (1969), indicated that, although experimentation is possible in the natural sciences, it is not in the social sciences: The comparison between social facts of the same category across societies is thus the key method to understand their nature. They contend that, through comparison, it is possible to overcome ideographic perspectives and engage in pure description in the social sciences. Comparison allows sociological objects that take into account their structural and functional determinations to be built (Schultheis 1989) - that is, to get closer to an explanatory approach. The crucial importance of historical time and place (and their comparison with other times and places) is therefore at the core of the life course perspective (Blossfeld 2009). Starting from the observation that "the life course of individuals is embedded in and shaped by their context" (Elder 1999:3), a 
comparative approach allows researchers to distinguish the effects that given sociocultural opportunities and constraints have on the trajectories of migrants' children from the effects of either individual characteristics and actions or the close social environment. The life course of migrants' children in modern societies is molded by the host country's institutions and structures (e.g., educational systems, patterns of employment, and national welfare-state regimes), and by the families' migration histories, cultures, and values. Comparison means explicitly modeling the way in which different kinds of institutions affect behavior.

Comparison is crucial in identifying both the influence that specific institutional contexts have on the processes under examination and the extent to which lifecourse mechanisms can be generalized across contexts. It is also important for researchers to step away from their usual sociocultural settings to gain perspective through confrontations with other empirical settings. Comparison is therefore a potentially key methodological tool in studying the trajectories and situations of the children of immigrants. The first requirement for comparing is a clear definition of the object of comparison. In the following, we discuss the multiple definitions of "children of immigrants" to determine which kinds of populations and which geographical settings are relevant to a meaningful comparison.

\subsubsection{Children of Immigrants: A Challenging Definition}

The first methodological issue is to define who the children of immigrants (i.e., the second generation) are and who should be the focus of the study, which is not a simple affair. The classical definition, elaborated in the United States during the 1940s, applies specifically to foreign immigrants' offspring, these children been born in the country of residence (Hutschingson 1953 quoted by Widgren 1986). Immigrants' children who arrived to the country of residence before compulsory school or during the early years of compulsory school are defined by authors such as Portes and Rumbaut (2006) as a different category - that is, the "one-and-a-half generation." Thus, scholars have introduced a distinction among the children of immigrants according to their relation to the country of residence: those who were born there versus those who arrived as children.

Definitions about which children of immigrants need specific attention from researchers are also very much influenced by the general context of the country of residence. First, laws on nationality lead to different definitions. For instance, in countries where the jus soli is the main form of acquisition of nationality, such as the United States or Canada, all immigrants' children born in these countries are considered part of the target population. They have the nationality of their country of birth and are expected to settle permanently in that country. Conversely, in countries where the jus sanguinis predominates, only migrants' children with a legal status of foreigners are considered part of the target category, and those who became nationals are "forgotten," at least by official statistics. This was the situation for a long time, until the early 2000s in the case of Switzerland (Bolzman et al. 2003). 
The definition of the target population is also influenced by dominant commonsense perceptions on migration in the receiving societies. Thus, in many European and North American countries, scholars focus their studies on children whose foreign immigrant parents are employed as blue-collar workers or unskilled workers in the country of residence or on children belonging to visible minorities. This practice associates the concept of children of immigrants with low social status or with particular ethnic groups. The challenge of defining the focus population is not only methodological but also substantive, especially when there is a risk of reinforcing social categories that contribute to the stigmatization of particular populations (Simmard 1999; Sayad 2006).

With globalization, the increase of geographical mobility, and the non-linearity of migration patterns, complex family situations highlight the limitations of classical definitions of migration. First, in the case of children where one of the parents is a migrant and the other is a non-migrant, can we still talk about "children of immigrants"? Do both parents need to be immigrants? Second, consider a woman who is born in the country of immigration of her parents and who immigrates to her country of origin, only to go back a second time to her country of birth. Can we still consider her a descendent of migrants, despite the many years spent in the country of origin of her parents? In other words, does continuity of residence matter for the definition?

\subsubsection{Comparative Designs}

Comparative research designs can be very diverse in terms of unit of analysis, the choice of which depends on the research purpose. There are important questions regarding the definition of the population subgroups and their geographical origin to focus on.

The first order of questions to be answered addresses the types of populations to compare. Scholars can be interested in comparing children of immigrants of one or several national origins with children of natives in order, for instance, to measure ethnic inequalities, the effectiveness of anti-discriminatory policies, or the progress of integration using children of natives as a reference population (Bolzman et al. 2003). Researchers may also be attentive to the differences between ways of incorporating the descendants of immigrants compared to the first generation of the same ethnic background in order to measure social mobility or social reproduction across generations (Portes and Fernandez-Kelly 2008; Bolzman et al. 2003). Another important comparison concerns the similarities and differences between cohorts of children of immigrants with different ethnic and national backgrounds in order to test the presence of a "segmented assimilation" pattern in a particular society (Portes and Zhou 1993, Chap. 3 in this volume). Contrasting the social trajectories of children of immigrants born in the country of residence (second generation) with children who arrived in the host country at a very young age (1.5 generation) may be a useful source of insight on the importance of socialization institutions in their 
trajectories. Scholars can also establish comparisons between children of immigrants of the same national origin by distinguishing those who became nationals of the country of residence from those who are still foreigners. Similarly, comparisons based on citizenship rights can also concern children of immigrants whose parents have grown up abroad despite being nationals of the country of immigration (for instance, ethnic Germans in Germany) in contrast to the children of foreign immigrants. Here, the aim is to measure the relation among juridical factors, social perceptions about the children of immigrants, and the outcomes of the second generation (Bolzman et al. 2003; Frauenfelder 2007). An additional possibility of such strategy is the comparison between children of returned immigrants with respect to those whose parents settled down in the country of residence. Here, the purpose can be to understand the influence of migratory projects and transnational practices of the first generation upon the second generation. Last but not least, the comparison can concern children of immigrants belonging to the same cohort from similar ethnic and social backgrounds who are socialized in the same area. In this case, sociodemographic factors need to be as homogenous as possible, and comparisons within individuals shed light on variations within the group (Santelli 2007).

The second order of methodological questions is related to the definition of the geographic unit of the comparative design. Most studies limit the comparison to the same geographical unit and vary the populations that are compared within this unit. In other cases, the comparison is between several local unities (urban, rural, administrative settings) at the national level. These comparisons are based on the conception that different variables associated to local contexts influence the trajectories and situations of children of immigrants. Such variables include for instance the presence of integration policies, educational policies, attitudes toward ethnic minorities, size of the localities, and heterogeneity of the population in terms of ethnic composition. These kinds of comparative designs are very frequent and often associated to research funded by public institutions and national research funds because they stay within the borders of the same state and they aim at advising national or local policies.

With the Europeanization of many social fields and the multiplication of destination countries, international comparisons also become more relevant. For instance, the situations of children of immigrants of the same ethnic origins in different national contexts are also observed in order to measure the respective influences of the contexts and different variables related to these ethnic groups in the analysis (Crul et al. 2012). More seldom, comparisons are conducted at the transnational level, which is more difficult to implement. Here, the transnational practices of children of immigrants with the same or different ethnic backgrounds are compared across several national contexts.

The study of children of immigrants obliges the researcher to address a number of methodological challenges and to make theory-informed comparisons rather than arbitrary or convenience-based research designs. Some contributions to this volume address these challenges directly. The chapter from Lessard-Phillips, Galandini, de Valk, and Fibbi touches on some of the issues mentioned above by reviewing the variety of choices made in major surveys including second-generation residents in 
Europe. They provide a comprehensive overview of the possible types, levels, and benchmarks for comparison; their availability in current European data on children of migrants and their relative advantages and disadvantages. The authors also focus on the impact that bias arising from selectivity, as well as age, period, duration, and cohort effects, can have on the data production and interpretation, and they offer potential methodological tools to analyze such data in a useful manner. They argue that in order to bring the field forward, meaningful second-generation research should include tools that make these comparisons more effective and lead to a deeper understanding of the processes at play for various groups (via more refined or varied methodological tools, as shown in this volume).

The chapter from Guarin and Rousseaux is a case study based on one country (Switzerland) in which comparison takes place among several subgroups (children of immigrants from several origins and children of natives on the one hand, children of immigrants and first generation residents on the other hand) on issues related to access to employment and labor-market status. Switzerland is an interesting case study because people with a migratory background (i.e., first- and second-generation residents) represent about half of the labor force. Using data for the Swiss Labour Force Survey (SLFS), the authors analyze the situations of different groups within the second generation on the labor market and explore the main factors that can influence their position. They suggest the use of data-mining tools in order to detect unexpected relations between variables. Their results show the importance of educational level of the father for predicting the employment situation of descendants. They also observe the existence of an "ethnic penalty" vis-à-vis some secondgeneration groups after controlling for several important variables (social origin, age, sex, and educational level).

The last chapter in this section from Milewski and Otto takes the opposite perspective and addresses the issue of the presence of a third person in survey interviews that were conducted with children of Turkish immigrant parents and their non-migrant counterparts. Data came from a project titled "The Integration of the European Second Generation" (TIES 2006-2008) from Germany, France, the Netherlands, Austria, Switzerland, and Belgium. The results show that when children of migrants are interviewed, it is significantly more common for a third person to be present besides the interviewer and the interviewee than in interviews with children of non-migrant. Furthermore, the characteristics of the third person vary between groups. These differences cannot be explained by differences in opportunity structures (i.e., type of housing, number of rooms, other people living in the household, all things that determine whether a person can be alone with the interviewer). The chapter also tests for the effect, during the interview, of a third presence on expressed attitudes. Results indicate that the presence of a bystander produces answers that vary from those given when the respondent is alone with the interviewer. The risk of item non-response is also higher in the presence of a third person. Thus, more attention should be granted to the micro-social conditions of data collection in research designs. 


\subsection{Life Course Perspective and Mixed-Methods Approaches in the Study of Children of Migrants}

Methodological choices necessarily correspond to researchers' theoretical perspectives and the nature of the phenomenon under study. In the case of the children of migrants, the extent and the ways in which the migration background of parents interplays with their transition to adulthood (e.g., their education, employment, and residential and family transitions) may explain why several chapters in this volume adopt an implicit or explicit sociological life-course perspective. It has been stressed that migration research does not interact much with life course research (Wingens et al. 2011, see also Chaps. 5 and 8 in this volume): on the one hand, the topic of migration does not constitute a strongly established object of research for life course scholars; on the other hand, the life course paradigm (Elder et al. 2003) has not had a deep echo in migration research until recently. One objective of this volume is to show how both fields are in fact intimately related, particularly when research methodology is concerned. In several chapters, longitudinal data, life history calendar, biographies, the usual methodological nuts and bolts of life course research, are critically employed and evaluated to analyze the integration of children of migrants.

\subsubsection{The Life Course Paradigm}

In several papers, Elder proposed and developed a set of five principles constitutive of what he calls "the life course paradigm" (1995: 101). Although scholars disagree whether a strong unified theory of life course exists (Wingens et al. 2011), Elder's principles give a theoretical direction that reflects their diverse preoccupations (Elder 1995; Elder et al. 2003; Elder and Giele 2009). These five principles are (1) lifelong human development, which means that cognitive development evolves during the whole life in interaction with other principles of the life course paradigm; (2) timing, which underlines that the consequences of a life event or transition change depending on the age at which they are experienced; (3) linked lives, which means that life courses of related persons are interdependent and affect each other; (4) time and place, which indicates that life courses are shaped by the institutional and historical contexts; and (5) agency, which means that individuals develop expectations, have a certain degree of choice, and act intentionally, in relation to the opportunities and constraints structured by the institutional contexts in which they live.

In his research, Elder was especially interested to analyze the effect of the economic depression of the thirties on the adolescent and adult trajectories, first in relation to the age this depression occurred when they were children and second in relation to the impact this crisis had on their parental household (Elder 1999). Even though Elder's research on the children of the Great Depression did not focus on the theme of migration, it could certainly be taken as a canonic model for research focusing on comparisons between children of immigrants and natives, between 
different groups of children of migrants, between generations of migrants, etc. In Elder's research, children are distinguished according to their "starting position" (Giele 2009: 251), i.e., whether they were children during the Great Depression or just before (Elder 1999). In the case of children of immigrants, this starting position can be related to their origin, their foreigner status, or their belonging to ethnic minorities; such starting position may be held from birth or acquired at the moment of arrival in the host country (Heath and Brinbaum 2007; Lagana et al. 2013). It can be also related to the social or geographical space and context where they are living during childhood, with its environment and opportunity structure (a suburban neighborhood, for example). Children of immigrants then grow up and become adults in a social context that shapes duties and rights, opportunities and constraints for foreigners or ethnic minorities in a specific way that could differ from those of natives or the ethnic majority and from the experience of their parents. Children of immigrants with the same starting position can develop divergent life course trajectories during their adolescence and their transition to adulthood.

Levy (2013:22) proposes to sketch the life course as a "sequence of status profiles." Here, the term of sequence involves a timing element that holds the signification of the life course as a movement in the social space. Status profile means that a person has different social participations in the economic sphere, in the family, etc., at each moment of his/her life. Each of the social places in which he/she participates is characterized by normative or institutional rules, as well as the position, especially the prestige, associated to the domain of participation and role set ascribed to this position, such as the related rights, duties, and expectations. Translating this perspective on the sequence of status profiles into research on the children of immigrants, social participation gains an additional dimension, since for these children it also means integration into different social spheres. Several questions specific to children of migrants may arise: Are movements and participations through social spaces ruled by implicit or explicit social barriers that selectively delay or hinder integration? Is there any kind of tension for children of migrants in role sets associated to their profile of status or between their status related to their foreign origin and their status related to the fact they are living in the host country?

\subsubsection{Life Course Designs}

Adhering to the principles of the life-course perspective is crucial to understanding social phenomena. It requires the adoption of coherent methodological choices and research designs that cover developments over time (intergenerational time), differences in contexts (across groups of migrants or institutional contexts), and the role of agency in structure (young peoples' aims and strategies). In addition, a special emphasis is given to the subjective perspective through which individuals report their biographical narrative of the events, transitions, and trajectories they experience in their life course. This is an important aspect to take into account because the children of migrants may navigate through life by making reference to a variety of 
sets of cultural norms and meaning systems (that may not necessarily be coherent with each other). In order to grasp this diversity and, especially, to be able to infer the ways in which it affects their transition to adulthood, we need explorative methods and in-depth case studies that focus on such subjectivity.

Scott and Alwin (1998) distinguish among three types of life history data collection in life course research (see also Levy et al. 2005). By type, they do not mean the different data collection designs used by researchers but the explicit aims researchers have when collecting data. The first type of data collection is centered on the notion of events. Life course events can be normative or expected, such as a marriage, the birth of a child, the transition to the labor market, or retirement, or nonexpected, such as an accident or a divorce. The event-centered type of data collection corresponds to collecting life events, their dates, their sequences, and the durations between them to analyze interactions and eventually spillover effects between the different domains of the life course (Courgeau and Lelièvre 1992). However, Scott and Alwin (1998) mention that this type of data collection, which is focused on events, is not limited to past events but also to people's eventual present situations and even to events that interviewees expect, or not, in their future.

The second type of data collection is related to the accumulation of experiences, which leads to some situations in the past or the present, or also to some expected situations in the future, such as an expected professional career after a specific educational degree. The notion of path dependency is the underlying element that drives the collection of this type of data (Di Prete and Eirich 2006; O'Rand 2009). Indeed, a position in the social space is defined by its structure of opportunities and constraints that leads or does not lead to a further step in the life course that engenders new opportunities or constraints, etc. The successive steps lead to a process of cumulative advantages or disadvantages across the life course. This type of data collection can be mobilized to analyze the path dependency that structures the life course from the starting position and status of being children of immigrants and to show the chain that links this starting position to adolescent and young-adulthood trajectories in the life domains of school, work, and family (Lagana et al. 2013).

The third type of data collection mentioned by Scott and Alwin (1998) is related to people's evaluations or interpretations of events and/or experiences, which can be oriented toward the past, present, and future. How do children of migrants evaluate their own trajectory, maybe in comparison to the life course of their native pairs in the country in which they live or to the life course of their parents, etc.?

Classically, we can distinguish two main designs of life course data collection: the retrospective design, in which the past biography of individuals is collected at one moment in time (Scott and Alwin 1998; Ruspini 2002); and the prospective design, in which people are followed up at regular time intervals to observe how their lives unfold. Much literature has already discussed the respective advantages and disadvantages of each perspective (Scott and Alwin 1998). Here, we limit ourselves to one major difference between the two designs. A retrospective approach is more event oriented (Blossfeld et al. 2007), in the sense that events and their dates of occurrence are the main focus of data collection. A prospective approach is more oriented toward individuals' holistic progression in the social space across time, and 
not only is his or her life development recorded but also his or her values, attitudes, and expectations about the future. In this way, without that having to be a strong rule, a retrospective design is more appropriate when the research focuses on event sequences (more "objective"), while a prospective design focuses on the accumulation of experiences (with consideration of the subjective dimensions of the life course as well). This distinction applies only partially to qualitative approaches, since in both retrospective and prospective designs, the aim is to collect information on respondents' evaluations and interpretations of their own life and experiences.

\subsubsection{Data Collection to Analyze the Life Courses of Children of Migrants}

The chapters of the second section of the book share a series of premises from which to begin. First, in a life-course perspective, individual trajectories are not only interdependent (the events occurring in one trajectory affect the events occurring in another trajectory) but also intertwined with the trajectories of relevant others (e.g., parents, partners, siblings, or peers, to name a few) who, in the case of children of migrants, may be living in the host country but also in the country of origin. This perspective emphasizes the need to explore the inter- and intragenerational linkages in the transition to adulthood of children of migrants. Second, the life-course perspective also focuses on the need to place trajectories in their historical and geographical context. Communities and institutions provide a structure of opportunities and constraints that frame possibilities for individual action and choice. Lastly, the life-course perspective underlines the subtle relationship between the individual and his or her context but gives importance to individual agency in making choices under the conditions of this context.

The first paper in this section, from Ingrid Tucci, analyzes various contexts (two different countries, France and Germany) and populations (Turkish and Middle Eastern origin in Germany; North African and Sub-Saharan origin in France). Yet, it uses intergroup comparisons to highlight one substantive interest: the extent to which the children of migrants are integrated into each of the two societies, given the different institutional educational systems and the processes determining such integration (or lack thereof). More precisely, this contribution aims to discuss the potential of using panel data in this field and of linking quantitative data with qualitative life-course data to grasp the individual, social, and institutional mechanisms underlying the educational trajectories as well as eventual turning points.

Attias-Donfut and Cook's chapter is based on a generational approach (the interlinked lives of life-course sociology) to the study of migrant families, in which migrant families are viewed as "fluid structures of intergenerational adaptation" (in this volume, p. 130). The chapter draws on two separate studies: a survey-based national study that examines economic transfers across generations between migrant parents and children, and a comparative qualitative study across three countries with 
focus groups of African migrants and their children that were centred on questions of citizenship and belonging. Even though there were no mixed methods and no longitudinal designs, the combined interpretation of different data sources (both in terms of the kinds of data collected and the sampling design across generations) was key to illustrating the roles that migrant families play in the integration and adaptation of the next generation as well as the ways in which migration affects family support relationships across generations. The comparative nature of the projects also allowed the differences produced by the different kinds of migration processes to be highlighted. In contexts like Britain and South Africa, where African migration has more often been the consequence of forced migration or a temporary move, migrants' return prospects were stronger than in France.

The chapter by Santelli discusses the use of a cohort approach to study the entry into adulthood of youngsters with a North African background who lived in a suburban area of France. In order to appreciate and understand their heterogeneous life trajectories and educational and professional integration, the author chose to focus on one specific cohort of children who grew up in the same quarter, shared the same social context, and lived through the same historical time at similar ages. The research design is longitudinal, retrospective, and mixed method in nature. A register-based sample of young men and women was interviewed by questionnaire, and a subsample received biographical interviews. The quantitative analyses allow a statistical overview of the precarious global labor market situation of these youngsters but also the identification of five different types of trajectories among them, which range from profiles of permanent exclusion to profiles of stable employment. The biographical interviews provide an entry into the ways in which critical passages are lived and experienced by the individuals. An analysis of the complex interplay of family, peers, and institutions, which accompany the individual through the occurrence of crucial events like educational failures or the loss of a job, helps to explain the different outcomes of an apparently homogeneous group of descendants of migrants.

The combination of biographical interviews and sequence analysis in Gomensoro and Burgos's chapter follows a similar design. Yet, in this case, the biographical interviews are partially based on a life event calendar, a specific tool conceived to facilitate the retrospective recollection of important events using parallel and sequential retrieval techniques at the same time (Belli and Callegaro 2009; Morselli et al. 2016). The chapter discusses the added value of the combined use of a life calendar and biographical in-depth interviews to examine the educational transitions of the children of Albanian-speaking migrants in Switzerland. The authors introduce the commonalities and differences of the life course and the biographical research perspectives and discuss the respective methodological tools of data collection associated with each of these two approaches. In Gomensoro and Burgos's research, the longitudinal retrospective data-collection tools are a life event calendar and narrative in-depth interviews, which are complementary, since they have and achieve different objectives. On the one hand, life calendars enhance the reconstruction of "objective" life-course trajectories, in which events and transitions are dated, factual information that shapes the duration of phases of stability and change in the 
trajectory, which can be quantitatively analyzed through sequence analysis, for example. On the other hand, narrative or biographical interviews retrieve a selection of subjectively significant moments in the individuals' biographies and focus less on their exact timing and more on the meaning that the individuals give to them in interpreting the unfolding of their life. The combination of objective and subjective information is often crucial to understand the crossing of individual meanings and strategies beyond behavioral choices (Bernardi 2011). Yet, the added value of using these specific two tools, the authors argue, consists of using the life event calendar as a basis for the interview (Engel et al. 2001; Glaser and Van Der Vaart 2009; Morselli et al. 2013). The advantages are that the graphical representation of the interviewee's complete life helps him or her to contextualize the interpretation of a specific event and to relate it to other ones, identify turning points, and develop a biographic narrative that is less dependent on the incipit question of the interviewer's guidelines.

Methodological choices and research designs not only correspond to specific research questions and theoretical perspectives but also to epistemological postures. Vats-Laroussi's chapter, based on the analysis of several studies on intergenerational relationships among migrants and their children, is a plea for an epistemology of meanings that attributes the greatest importance to the individual interpretations and social interactions in explaining social phenomena. A direct consequence of such an epistemological position is the suggestion of a constructivist approach to the research design, which translates into focusing "on the reconstruction of multigenerational trajectories and the social networks of migrants before, during and after the move from one country to another." These would be the channels through which knowledge is produced, intercultural competences are built, and new practices and family memories are created. The employment of multicultural and multigenerational teams as well as the implications of professionals and actors in the data-collection and interpretation phases are a direct consequence of such premises. According to the author, such teams would have the necessary sensitivity to collectively produce a valid interpretation of the evidence.

\subsection{The Biography and Identity of Second-Generation Residents as a Negotiation Process}

The use of nationality and, sometimes, ethnicity as criteria to analyze the integration of migrant groups, especially in quantitative methods, is not without methodological risks. Indeed, the strongest risk of this kind of approach is of naturalizing a migrant group and attributing a collective characteristic to an individual, such as being Polish, African American, and so on. Such a methodological process corresponds to giving a cultural identity, if not a biological identity, to each person belonging to the group under investigation. It also corresponds to the implicit expectation that each person of an immigrant group will develop a common or average 
behavior of integration. Such a methodological posture contradicts elements of the life course paradigm, which we already enumerated, especially the principles of time and place, linked life, and agency (Elder et al. 2003). Moreover, it also contradicts the methodological posture in life course research that analyzing variability in one group is a main aim in comparative research (Blossfeld 2009; Giele 2009). In a similar way, nationality naturalizes the ways in which children of immigrants make sense of their lives and how they position themselves in the host society.

Qualitative investigations, as proposed in the chapters by Mey and by Aparicio and Tornos, show that this process of statistical categorization by a sole nationality is much too simplistic, especially in the case of children of immigrants. Qualitative life stories present the triple interest of giving the comprehensiveness of the social and individual life; investigating the subjectivity of persons, especially how they give sense to events of their life; and investigating the narrative form they use to describe change in their life (Kohli 1981; Giele 2009).

In the chapter by Mey, past life experiences are the subject of interpretations and reinterpretations by children of migrants across their life course that contribute to the subjective interpretation of own life. The author adopts the theoretical perspective of Schütze (2007). In this perspective, collected biographies reflect the subjective experiences and expectations of individuals in interaction with their environment. The chapter is devoted to analyzing the self-processes of sense making and selfpositioning during the transition to adulthood of 34 children of immigrants living in the locality of Emmen, situated in the German-speaking canton of Lucerne in Switzerland. The author proposes a biographical qualitative approach to reconstruct the ways in which the respondents' biographies developed in the specific context of the city of Emmen. In particular, the methodology allows the investigation of the resources mobilized in relation to the strategies chosen by the individuals while their life trajectories unfold. The author proposes an analysis of narratives made by each interviewed person. The prospective design, in which people were interviewed twice, allowed the processes of sense making and self-positioning to be understood. In developing an analysis of a young Albanian's biography, Mey shows mechanisms of exclusion and auto-exclusion at each phase of his life course during his adolescence.

The chapter by Aparicio and Tornos shows how the construction of the self, and its eventual evolution across the life course, depends on interactions at several levels, especially social interactions with people who are representative of institutions with which children of migrants are in contact (teachers, apprenticeship referents, etc.). The chapter develops the difficult question of the identity of second-generation individuals under the prism of the relation between the construction of the self and exclusion/inclusion in the society of the country of residence. The authors propose a qualitative approach, arguing that it allows the identity to be investigated as a negotiation process. A pilot survey was then done in the region of Madrid, in which young second-generation residents were interviewed. In this way, the authors show that identity is a complex notion that cannot be resumed in a binary characteristic (to have the national identity of one's parents or not). Three types of negotiations of 
identity made by the interviewed people are explored: within the family, with the interviewer, and with the interviewed people themselves.

From these two chapters, one can generalize that the identity or the self that belongs or does not belong to a group depends on the place of residence, which is embedded not only in a country but also, as suggested in the chapter by Santelli, at an infra-scale level (e.g., a province, city, or quarter) or at a macro level (e.g., a region or continent). The identity is not necessarily a national identity but, in some cases, an identity as an immigrant. The results of these two chapters suggest, in coming back to quantitative surveys, the use of some instruments developed in social psychology, including, for example, questions about the identity related to the place of residence, which can be situated at different levels, from the city to the continental region. Social interactions and barriers can also be investigated with instruments like the Bogardus scale of social distance (Bogardus 1947), with which people are asked whether they would agree to work with, be the friend of, or marry someone belonging to another nationality.

\subsection{Transnational Approach and the Second Generation: Beyond Methodological Nationalism}

\subsubsection{Beyond Methodological Nationalism}

As mentioned above, the term "second generation" implies a number or ranking of generations in a country of residence, computed by starting from settled immigrants. The methods used to analyze the integration of second-generation individuals come under what is called methodological nationalism (Wimmer and Glick Shiller 2003). Methodological nationalism is defined, in the chapter of Levitt, Lucken, and Barnett, as "the tendency to accept the nation-state and its boundaries as a given in social analysis" (in this volume, p. 255). However, most children of migrants live in a transnational field, between the culture of the parents' country of origin and that of the country of residence, in such a way that both the residence and home countries become fuzzy to define. Second-generation individuals often circulate during their life course between (at least) these two social, geographical, and cultural spaces. For example, during their childhood, they spend holidays in the country of origin, where they have contact with relatives living in that country (cousins, uncles, etc.).

Transnational contacts between relatives even exist even in the case of longdistance migration. The classic Polish Peasant shows that even at the time of heavy European migration to the United States at the beginning of the twentieth century, migrants exchanged letters with their relatives who remained in the country of origin (Thomas and Znaniecki 1920; Tucci, Chap. 5, this volume). These epistolary exchanges show the continuation of obligations among migrants toward those who did not migrate, which cumulated with new obligations in the country of domicile 
(Giele 2009). At the beginning of the twenty-first century, other media, like the Internet, e-mails, video conferencing, cell phones, and more generally information and communications technology (ICT), allow immaterial contact between secondgeneration individuals and people who remained in the country of origin (Nedelcu 2010). The development of air transportation in recent decades mitigated and shortened the distances, while channels of money circulation became easier to use and increasingly secure. Migrants as well as their children use all of these techniques to continue their obligations with their relatives who remain in the origin country.

\subsubsection{Transnational Designs}

The transnational research regarding the children of immigrants is often a one-case monograph. In this book, the chapters claiming a transnational approach are about the cases of second-generation individuals of Spanish descent growing up in Switzerland or of second-generation people of Indian descent living in the United States. The transnational approach corresponds to another way of investigating the multiple belonging of second-generation individuals and their identity.

Levitt, Lucken, and Barnett's ${ }^{1}$ chapter is about the space of imagined traditions in the religion of second-generation Indian Americans living in the United States. Using data from 30 qualitative interviews with Gujarati-origin Hindu and Muslim women undergraduate and graduate students, aged 18-29, who live in the Boston metropolitan area, the authors show that these second-generation individuals have links with their relatives who live in the origin country and even in other places worldwide. These links-for example, with their grandparents-allow these second-generation Indian Americans to have knowledge of and eventually practice their original religion or to identify with it. Despite their distance, people in the origin country can play a significant role during the life course of children of migrants. However, practices are embedded in the context of how religion is institutionalized within the American way of life, which means that Hinduism and Islam are subject to reinterpretation in comparison to what they are in India. Here, the solidity of the theoretical perspective (transnationalism) combined with the use of a classical methodological perspective (semi-structured interviews) allows for indepth original knowledge to be produced about "lived religion" experiences (Cadge and Ecklund 2007) and for a typology of "religious assemblages" to be elaborated. This chapter also shows that the notion of comparison is not absent from a transnational perspective, as the authors compare religious practices and their meaning between grandparents and their grandchildren.

The aim of the chapter by Richter and Nollert is to discover the links of secondgeneration people of Spanish descent living in Switzerland with the country of origin. What kind of memories could they have of Spain? In this ethnographic research, various materials were collected, including biographical interviews with

\footnotetext{
${ }^{1}$ Originally published in the peer reviewed journal, Mobilities, in 2011.
} 
second-generation respondents, interviews with some of their relatives in Spain, visits to and photographs of the geographical sites where the second generation used to go in Spain (e.g., a beach or a street) made by the researchers, and new interviews of second-generation respondents and their confrontation with the material collected in Spain. This very sophisticated data-collection methodology allowed the authors to obtain rich and mixed data for analysis.

The last chapter of the book by Mazzucato, Dankyi, and Poeze does not focus on second-generation individuals per se but on the case of children who remained in the country of origin while their parents migrated. These parents did not migrate with their children because of the uncertainty of the migration, their undocumented status, or the difficulty of meeting the requirements for family reunification. The chapter focuses on cases in which the children are young, which means an organization and negotiation of the co-parentage in the country of origin. As in the case of the analysis of second-generation individuals, such research on the circulation of migrants requires data from different sites, at least from the place where the migrant parents are living and the place where the children are being educated. In this case, the actors investigated are very similar to those in the case of transnational analysis of the second generation: children, parents, and relatives, especially grandparents, which in this last case play an important role. Other kinds of circulation are also investigated, like the circulation of money from migrants to the people who educate their children. This last contribution opens new perspectives in the study of intergenerational relations in a transnational setting. It provides a useful method for analyzing the often multiply located relevant others for migrant children.

\subsection{Future Research}

This collective book makes a series of first steps to open up research on children of immigrants to issues that deserve more in-depth exploration. We retain at least four issues here without pretending to work out all of the paths opened by the contributors in this volume. The first central issue is the identification of the relevant populations to be studied when the research focus is the children of immigrants. Given the dominant methodological nationalism (see above), most researchers have studied the situations of children of migrants who were born in the country of destination or arrived there in their early childhood (see, e.g., Portes and Rumbaut 2006; Crul et al. 2012). Less attention has been granted to children who were left behind. However, even though these children have not migrated themselves, they experience migration through the separation from one or both of their parents. The transnational perspective underlines the need to consider this issue more seriously. The chapter from Mazzucato and colleagues in this volume is a good example of this perspective that deserves more empirical studies - in particular, more systematic comparisons between children who migrated with their parents and children whose families did not experience migration. Similarly, when addressing the complexity of parental backgrounds and migration patterns, we need more exploration of the life 
courses of children born from binational couples and of children of migrants who have experienced geographical mobility between two or more societies. Particular attention should be paid to the ways in which these persons build their identities and feelings of belonging in complex and changing environments.

The second issue that needs more attention is the later life trajectories of children of migrants. A large part of the contributions in this volume are, in fact, devoted to the integration of the massive growing population of the children of migrants in European countries, which is a new social phenomenon, in comparison to North American countries, in which immigration is ancient and structural. Until now, most studies have focused on the educational paths of the second generation, their transition to adulthood, or their family enlargement. Thus, children of immigrants' access to employment, time of leaving the parental home, and creation of their own family have been systematically examined (Bolzman et al. 2003; Collet and Santelli 2012; Crul et al. 2012). Of course, this stage is crucial in individual lives and justifies significant attention. However, there are only a few studies about the descendants of migrants in later periods of life. Knowledge in this area deserves to be completed with either longitudinal studies or specific surveys. Particular consideration should be granted to gender perspectives to understand how social roles, gaps, and inequalities between men and women are constructed during adulthood among people with different ethnic and social backgrounds. Moreover, research on young adult children of migrants shows how they are disadvantaged during their transition to adulthood, and research has to show if these disadvantages persist during late adulthood and retirement as well as the different processes of accumulation of disadvantages during the overall life course.

The third issue under research is the field of intergenerational relations, which has an important place in our volume. A central concept that summarizes the variety of intergenerational relations is "transmission." Our book opens up a broader perspective on transmissions, in terms of the object of transmissions, who is involved, and what direction the process takes. While most studies focus on the unidirectionality of the transmission, which would go either from younger people (who would experience "modernity") to older people or vice versa from older people (who would experience "tradition") to younger (see Vatz Laaroussi 2015 for a critical review), the authors in this volume stress the need to consider transmissions as multidirectional as well as multidimensional (at economic, cultural, affective, and social levels) and thus more as forms of multilevel circulation. Transmissions should be seen as intergenerational and intra-generational as well as upward and downward; each generation member can be both a transmitter and receiver of multilevel exchanges. Generations "generate" stories and participate through their exchanges in a constant reinvention of "tradition" but also of "modernity." They revisit and reexamine the past to understand the present and project into the future, but the challenges of the present reality also mend the intergenerational frame. This perspective is extremely stimulating for empirical approaches, since it invites researchers to be more open to the diversity of links that are forged between and within generations in various contexts and situations. Researchers need methodological 
creativity, especially using qualitative approaches or mixed methods, to capture the complexity of intergenerational relations.

The fourth issue, which is directly related to intergenerational transmission, is the view of the family to which the children of migrants belong. The sociology of the family underlines the necessity of having a more complex view of what a family is and to be aware that family and households, which are often considered overlapping realities, may be very distinct ones. In fact, if the family is very often part of the same household, then family ties extend beyond co-residential ties (Widmer 2010). Family relations exist beyond the household and can include a wide range of relatives who may be perceived as being part of the family. Moreover, the transnational perspective suggests that families can exist across borders, living through parallel and only partially overlapping physical, social, and mental ties. Thus, for example, individuals can be part of a transnational family characterized by the dispersion of its members among several nation states and by the relational interdependence between them despite the distance (Wall and Bolzman 2013). Indeed, migration does not remove the links between family members who have left one country and those who remained in that country (Vatz Laaroussi and Bolzman 2010). In fact, despite the distance and duration of the separation, various forms of relations develop between relatives, including intergenerational relations. Their resources can travel across borders, and their network chains are maintained. Thus, more complex methodological tools are needed to capture the complexity of family relations in contemporary mobile societies, especially the place of children of migrants in these configurations.

The attention granted to methodology is not only important for future research but also highly relevant for social and integration policies in at least four ways. First, the comparative perspectives may highlight the weight of institutional contexts in shaping the educational or professional paths of children of immigrants from the same origin (Crul et al. 2012) and therefore in their chances to have access to equal opportunities. Second, relying on longitudinal designs allows for the identification of critical turning points in the life course of children of immigrants (Gomensoro and Bolzman 2015) and offers tools to imagine how to create opportunities and reduce constraints at these key moments. Third, the analysis of children of immigrants' lives not only as individual pathways but also as the result of "linked lives" embedded in broader social relations, especially in intergenerational relations, sheds light on the necessity for policy makers to take these relations into account as being central for the second generation to build a meaningful place for themselves in the host country of their parents. Last, the transnational perspective underlines the fact that, in a globalized world, integration is not opposed but rather complementary to the maintaining of links with the country of origin. It also opens up the possibility to more innovative policies that can relate individuals and societies across borders.

This book can only be a plea for further research on how we study the ways in which integration and transnational processes are articulated in the lives of the second generation. There is enough empirical evidence about the fact that these processes are not exclusive but complementary (Levitt and Waters 2002), yet there is a 
lack of longitudinal studies about the transformation of these relations through time and how different life course stages influence the kinds of ties with the country of origin as well as the forms of participation within the resident society.

Acknowledgments This paper benefited from the support of the Swiss National Centre of Competence in Research LIVES-Overcoming Vulnerability: Life Course Perspectives, which is financed by the Swiss National Science Foundation (Grant number: 51NF40-160590).

\section{References}

Belli, R. F., \& Callegaro, M. (2009). The emergence of calendar interviewing: A theoretical and empirical rationale. In R. F. Belli, F. Stafford, \& F. D. Alwyn (Eds.), Calendar and time diary methods in life course research. Thousand Oakes: Sage.

Bernardi, L. (2011). A mixed-methods social networks study design for research on transnational families. Journal of Marriage and Family, 73(4), 788-803.

Blossfeld, H.-P. (2009). Comparative life course research cross national and life course perspective. In G. H. Elder Jr. \& J. Z. Giele (Eds.), The craft of life course research (pp. 280-306). New York/London: The Guilford Press.

Blossfeld, H., Golsch, K., \& Rohwer, G. (2007). Event history analysis with Stata. Mahwah: Lawrence Erlbaum.

Bogardus, E. S. (1947). Measurement of personal-group relations. Sociometry, 10(4), 306-311.

Bolzman, C., Fibbi, R., \& Vial, M. (2003). Secondas - Secondos. Le processus d'intégration des jeunes adultes issus de la migration espagnole et italienne en Suisse. Zurich: Seismo.

Cadge, W., \& Ecklund, E. (2007). Immigration and religion. Annual Review of Sociology, 33(1), 359-379.

Collet, B., \& Santelli, E. (2012). Couples d'ici, parents d'ailleurs. Parcours de descendants d'immigrés. Paris: Presses universitaires de France.

Courgeau, D., \& Lelièvre, E. (1992). Event history in demography. Oxford: Oxford University Press.

Crul, M., Schneider, J., \& Lelie, F. (2012). The European second generation compared. Does the integration context matter? Amsterdam: Amsterdam University Press.

Di Prete, T., \& Eirich, G. (2006). Cumulative advantages as a mechanism of inequality. A review of theoretical and empirical development. Annual Review of Sociology, 32, 271-297.

Durkheim, E. (1904). Les règles de la méthode sociologique. Paris: PUF Presses Universitaires de France.

Elder, G. H. (1995). The life course paradigm: Social change and individual development. In P. Moen, G. H. Elder, \& K. Lüscher (Eds.), Examining lives in context. Perspectives on the ecology of human development (pp. 101-139). Washington, DC: American Psychological Association.

Elder, G., Jr. (1999). Children of the great depression. Social change in life experience. Boulder: Westview Press.

Elder, G. H., Jr., \& Giele, J. Z. (2009). Life course studies. An evolving field. In G. H. Elder Jr. \& J. Z. Giele (Eds.), The craft of life course research (pp. 1-28). New York/London: The Guilford Press.

Elder, G. H., Jr., Johnson, M. K., \& Crosnoe, R. (2003). The emergence and the development of the life course. In J. T. Mortimer \& M. J. Shanahan (Eds.), Handbook of the life course (pp. 12-19). New-York: Plenum Press.

Engel, L., Keifer, M., \& Zahm, S. (2001). Comparison of a traditional questionnaire with an icon/ calendar-based questionnaire to assess occupational history. American Journal of Industrial Medicine, 40(5), 502-511. 
Fauconnet, P., \& Mauss, M. (1969). Sociologie. Paris: Les Editions de Minuit.

Frauenfelder, A. (2007). Les paradoxes de la naturalisation. Paris: L'Harmattan.

Giele, J. (2009). Life stories to understand diversity. Variations by class race and gender. In G. H. Elder Jr. \& J. Z. Giele (Eds.), The craft of life course research (pp. 236-257). New York/ London: The Guilford Press.

Glaser, T., \& Van der Vaart, W. (2009). Applications of calendar instruments in social surveys: A review. Quality \& Quantity, 43(3), 333-349.

Gomensoro, A., \& Bolzman, C. (2015). The effect of the socioeconomic status of ethnic groups on educational inequalities in Switzerland: Which "hidden" mechanisms? Italian Journal of Sociology of Education, 7(2), 70-98.

Heath, A. F., \& Brinbaum, Y. (2007). Guest editorial: Explaining ethnic inequalities in educational attainment. Ethnicities, 7, 291-304.

Kohli, M. (1981). Biography: Account, text, method. In D. Bertaux (Ed.), Biography and society. The life history approach in the social sciences (pp. 61-75). Beverly Hills: Sage.

Lagana, F., Chevillard, J., \& Gauthier, J.-A. (2013). Socio-economic background and early postcompulsory education pathways: A comparison between natives and second-generation immigrants in Switzerland. European Sociological Review, 30(1), 18-34.

Levitt, P., \& Waters, M. (Eds.). (2002). The changing face of home. The transnational lives of the second generation. New York: Russel Sage Foundation.

Levy, R. (2013). Analysis of life courses - A theoretical sketch. In R. Levy \& E. Widmer (Eds.), Gendered life courses between standardization and individualization. A European approach applied to Switzerland (pp. 13-36). LIT: Wien.

Levy, R., Ghisletta, P., Le Goff, J.-M., Spini, D., \& Widmer, E. (2005). Incitation for interdisciplinarity in life course research. In R. Levy, P. Ghisletta, J.-M. Le Goff, D. Spini, \& E. Widmer (Eds.), Towards an interdisciplinary perspective on the life course (pp. 361-391). Amsterdam/ Boston: Elsevier. Coll Advances in Life Course Research, vol. 10.

Morselli, D., Spini, D., Le Goff, J. M., Gauthier, J.-A., Brändle, K., Mugnari, E., Dasoki, N., Roberts, C., Bernardi, L., Bühlmann, F., Ryser, V.-A., Tillmann, R., Kühr, J., \& Bumbaru, A. (2013). Assessing the performance of the Swiss panel LIVES calendar: Evidence from a pilot study. LIVES working papers, 28, 1-56. doi:10.12682/lives.2296-1658.2013.28.

Morselli, D., Dasoki, N., Gabriel, R., Gauthier, J.-A., Henke, J., \& Le Goff, J.-M. (2016). Using life history calendars to survey vulnerability. In M. Oris, C. Roberts, D. Joye, \& M. ErnstStähli (Eds.), Surveying human vulnerabilities across the life course (pp. 177-199). New York: Springer.

Nedelcu, M. (2010). (Re)penser le transnationalisme et l'intégration à l'ère du numérique. Vers un tournant cosmopolitique dans l'étude des migrations internationales? Revue Européenne des Migrations Internationales, 26(2), 33-55.

O'Rand, A. M. (2009). Cumulative processes in the life course. In J. Z. Giele \& G. H. Elder (Eds.), Methods of life course research. Qualitative and quantitative approaches (pp. 121-140). Thousand Oaks/London/New Delhi: Sage Publications.

Piore, M. (1979). Birds of passage. Migrant labour in industrial societies. Cambridge: Cambridge University Press.

Portes, A., \& Fernandez-Kelly, P. (2008). No margin for error: Educational and occupational achievement among disadvantaged children of immigrants. Annals of the American Academy of Political and Social Science, 620(1), 12-36.

Portes, A., \& Rumbaut, R. (2006). Immigrant American: A portrait (3rd ed.). Berkeley: University of California Press.

Portes, A., \& Zhou, M. (1993). The new second generation: Segmented assimilation and its variants. Annals of the American Academy of Political and Social Sciences, 530, 74-96.

Ruspini, E. (2002). Introduction to longitudinal research. London: Routledge.

Santelli, E. (2007). Grandir en banlieue: Parcours et devenir des jeunes Français d'origine maghrébine. Paris: Ed. CIEMI.

Sayad, A. (1991). L'immigration ou les paradoxes de l'altérité. Bruxelles: De Boeck Wesmael. 
Sayad, A. (2006). Les enfants illégitimes. Paris: Editions Raisons d'Agir.

Schultheis, F. (1989). Comme par raison - comparaison n'est pas toujours raison. Pour une critique sociologique de l'usage social de la comparaison interculturelle. Droit et Société, 11(11/12), 217-246.

Schütze, F. (2007). Biography analysis on the empirical base of the autobiographical narratives: How to analyze autobiographical narrative interviews. Part 1 und 2. INVITE - Biographical Counseling in Rehabilitative Vocational Training. Further Education Curriculum. EU Leonardo da Vinci Programme. http://www.biographicalcounselling.com/download/B2.1.pdf. Accessed 13 Aug 2015.

Scott, J., \& Alwin, D. (1998). Retrospective versus prospective measurement of life histories in longitudinal research. In J. Z. Giele \& G. H. Elder (Eds.), Methods of life course research. Qualitative and quantitative approaches (pp. 98-127). Thousand Oaks/London/New Delhi: Sage Publications.

Simmard, M. (1999). Définir la jeunesse d'origine immigrée: réflexions critiques à propos du concept de deuxième génération. In M. Gauthier \& J.-F. Guillaume (Eds.), Définir la jeunesse ? D'un bout à l'autre du monde (pp. 121-143). Sainte-Foy: Les éditions de l'IQRC.

Thomas, W. I., \& Znaniecki, F. W. (1920). The polish peasant in Europe and America. Monograph of an immigrant group. Disorganization and reorganization in Poland. Boston: Badger.

Vatz Laaroussi, M. (Ed.). (2015). Les rapports intergénérationnels dans la migration. Québec: Presses de l'Université de Québec.

Vatz Laaroussi, M., \& Bolzman, C. (2010). Familles immigrantes et réseaux transnationaux: des articulations théoriques aux stratégies politiques. Lien Social et Politiques, 64, 7-25.

Wall, K., \& Bolzman, C. (2013). Mapping the new plurality of transnational families. A life course perspective. In L. Baldassar \& L. Merla (Eds.), Transnational families, migration and the circulation of care. New York/London: Routledge.

Widgren, J. (1986). The position of the "second generation migrants" in Western Europe. Studi Emigrazione, 3(81), 7-20.

Widmer, E. (2010). Family configurations. A structural approach to family diversity. Farnham: Ashgate.

Wimmer, A., \& Glick Shiller, N. (2003). Methodological nationalism, the social sciences and the study of migration: An essay in historical epistemology. International Migration Review, 37(3), 576-610.

Wingens, M., de Walk, H., Windzo, M., \& Aybek, C. (2011). The sociological life course approach and research on migration and integration. In M. Wingens, M. Windzio, H. de Walk, \& C. Aybek (Eds.), A life course perspective on migration and integration (pp. 1-26). Dordrecht/ Heidelberg: Springer.

Open Access This chapter is licensed under the terms of the Creative Commons Attribution 4.0 International License (http://creativecommons.org/licenses/by/4.0/), which permits use, sharing, adaptation, distribution and reproduction in any medium or format, as long as you give appropriate credit to the original author(s) and the source, provide a link to the Creative Commons license and indicate if changes were made.

The images or other third party material in this chapter are included in the chapter's Creative Commons license, unless indicated otherwise in a credit line to the material. If material is not included in the chapter's Creative Commons license and your intended use is not permitted by statutory regulation or exceeds the permitted use, you will need to obtain permission directly from the copyright holder.

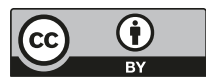

